\title{
Šta nam novo donose preporuke za STEMI 2017?
}

\author{
Mila Kovačević1,2, Ilija Srdanović1,2, Robert Jung ${ }^{1,2}$ \\ ${ }^{1}$ Institut za kardiovaskularne bolesti Vojvodine, ${ }^{2}$ Medicinski fakultet, Univerzitet u Novom Sadu
}

Sažetak Verovatno nema oblasti medicine u kojoj postoji toliko podataka koji su dobijeni na osnovu velikih,
dobro izvedenih randomizovanih studija, nego što je dijagnostika i lečenje bolesnika sa akutnim infar-
ktom miokarda. Osim toga, nigde u medicini se najnoviji tehnološki pronalasci i celokupna organiza-
cija lečenja nisu tako snažno stavili u službu lečenja kao kad je u pitanju lečenje akutnog infarkta.
Svakih pet godine, kada se nakupi novo znanje i rezultati velikih randomizovanih studija izlaze nove
preporuke Evropskog društva kardiologa iz određenih kardiovaskularnih oblasti. Ove godine su izašle
i nove preporuke za dijagnostiku i lečenje akutnog infarkta miokarda sa ST elevacijom (STEMI) i slo-
bodno možemo reći da su to preporuke koje su zasnovane na najviše dokaza od svih preporuka i da su
napisane veoma praktično i korisno. U ovom kratkom prikazu su prikazane ukratko novine iz Evropskih
STEMI preporuka. Zahvaljujući katedri za Kardiologiju Univerziteta u Beogradu je prevedeno i džepno
izdanje preporuka koje je izuzetno korisno za svakodnevni rad.
Ujedno želimo i sve da potsetimo na ljude koji su imali hrabrosti i znanja da 1982. godine urade
primarnu balon angioplastiku u infarktu srca u kateterizacionoj sali Instituta za kardiovaskularne
bolesti Sremska Kamenica na čelu sa doktorom Sretenom Grujičićem.

Uvod

a rastućom primenom reperfuzione terapije, pre svega primarne perkutane koronarne intervencije (PPCl), kao i modernom antitrombotskom terapijom, poslednjih godina beleži se opadajući trend kada je u pitanju smrtnost od STEMI. Ipak, mortalitet je i dalje visok i iznosi između 4 i $12 \%{ }^{1}$.

Nove preporuke za lečenje STEMI Evropskog kardiološkog udruženja obuhvataju revidirane koncepte prethodnih preporuka iz 2012. godine, promenu klasa prethodnih preporuka, kao i potpuno nove preporuke.

\section{Novi/revidirani koncepti}

Kako bi se nastavilo sa trendom smanjenja mortaliteta od STEMI, neophodno je pravovremeno postavljanje dijagnoze i pravovremena reperfuziona strategija, bilo da je u pitanju hemijska [fibrinolitička] ili mehanička (perkutana koronarna intervencija) reperfuzija.

\section{Dijagnoza STEMI- " 0 " vreme}

Dijagnoza STEMI se postavlja u momentu zabeležene elevacije ST segmenta (ili njenog ekvivalenta) na elektrokardiogramu (EKG) i upravo ovaj momenat, nezavisno od vremena početka tegoba pacijenta, predstavlja „nulto” vreme od koga započinje odbrojavanje, za razliku od prethodnog vodiča za STEMI gde je „nulto” vreme predstavljalo momenat prvog medicinskog kontakta (eng. first medical contact-FMC). Vreme od FMC do postavljanja dijagnoze STEMI trebalo bi daiznosi manje od 10 minuta. Novim preprorukama su jasnije difinisani i EKG kritrerijumi, izjednačavanje bloka leve i desne grane Hisovog snopa (ekvivalent elevacije ST segmenta), kao kriterijuma za urgentnu koronarografiju.

\section{Reperfuziona terapija}

Osnovnu odrednicu koja će opredeliti vrstu reperfuzije predstavlja mogućnost izvođenja primarne $\mathrm{PCI}$ (PPCl) unutar vremena od 120 minuta. Ukoliko se PPCl ne može uraditi u predviđenom vremenu, indikovana je fibrinolitička terapija unutar 10 minuta od postavljanja dijagnoze STEMI. Ovo vreme od 10 minuta određeno je na osnovu medijane vremena od randomizacije do davanja bolusa fibrinolitika u STREAM studiji, koje je iznosilo 9 minuta $^{2}$. U prethodnom ESC vodiču za STEMI ${ }^{3}$ vreme do davanja fibrinolitičke terapije iznosilo je 30 minuta, ali se računalo od FMC, a ne od postavljanja dijagnoze.

Nakon fibrinolitičke terapije preporučuje se rana rutinska koronarografija sa posledičnom $\mathrm{PCl}$ za sve pacijente. Navedena strategija smanjila je stopu reinfarkta i rekurentne ishemije u poređenju sa ranijom strategijom „gledanja i čekanja”, koja je preporučivala koronarografiju samo u slučaju spontane ili indukovane ishemije. Vremenski okvir kada bi, prema novim preporukama, trebalo uraditi koronarografiju i $\mathrm{PCl}$ iznosi od 2 do $24 \mathrm{~h}$, nakon fibrinolize. ${ }^{2}$

Preporučuju se fibrin specifični fibrinolitici, kao što je tenekteplaza (TNK-tPA), pri čemu je doza ista za sve pacijente, osim za starije od 75 godina za koje se preporučuje polovina doze.

Ukoliko se PPCl može izvesti u vremenu od $120 \mathrm{mi}-$ nuta od "0" vremena, indikovana je PPCl uz direktan transfer pacijenta u kateterizacionu laboratoriju, čime se skraćuje vreme za 20 minuta od FMC do prolaska žice kroz okludiranu koronarnu arteriju. ${ }^{4}$ Iz aktuelnog vodiča, izbrisan je termin „door to balloon” vreme. 


\section{CorbusNeich ${ }^{\mathrm{m}}$}

$\overline{\text { Pioneers in life-changing technologies }}$

\section{COMBO \\ DUAL THERAPY STENT}

\section{True Vessel Healing Matters}
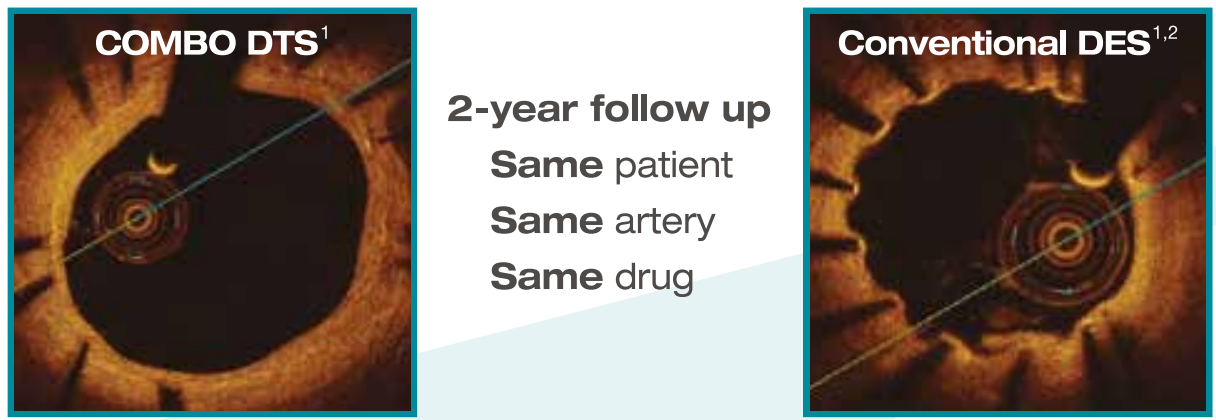

\section{Not All Stents Heal Equally}

\section{SA P P P H I R E"
Cronary oilatation catheter
Crossing Lesions Matter}

Unparalleled Balloon Profile for

Crossing Tight Lesions with Ease 


\section{Vremenski okvir za otvaranje infarktne arterije}

Kada je u pitanju vreme otvaranja infarktne arterije (eng. infarct related artery-IRA), period od $0-12 \mathrm{~h}$ je i dalje imperativ za izvođenje reperfuzione terapije (Klasa I). Istoj klasi pripadaju i pacijenti sa znacima prolongirane ishemije, sa hemodinamskom nestabilnošću i životno ugrožavajućim aritmijama (Klasa I). Rutinska PCl se može razmotriti kod svih pacijenata sa kasnom prezentacijom, 12-48h nakon početka tegoba (Klasa Ila), ali se rutinska $\mathrm{PCl}$ i otvaranje okludirane IRA ne preporučuje nakon $48 \mathrm{~h}$ od početka tegoba (Klasa III), već se tretira kao hronična totalna okluzija.

\section{MINOCA}

Aktuelne preporuke prepoznaju novi entitet - MINOCA (eng. myocardial infarction with non-obstructive coronary arteries), koji podrazumeva odsustvo signifikantne stenoze (stenoza $\geq 50 \%$ ) koronarnih arterija u uslovima koji zadovoljavaju kriterijume za postavljanje dijagnoze STEMI. ${ }^{5}$ Ovaj entitet zahteva dodatne dijagnostičke testove kako bi se postavila dijagnoza i sprovela odgovarajuća terapija.

\section{Izmenjene preporuke}

\section{Vaskularni pristup}

Kada je u pitanju vaskularni pristup, transradijalni pristup, zahvaljujući MATRIX ${ }^{6}$. studiji koja je samo učvrstila rezultate RIVAL' i RIFLE-STEACS ${ }^{8}$, postaje pristup izbora sa većim nivoom dokaza (iz Klase lla prelazi u Klasu I).

\section{DES vs BMS}

Prilikom izbora stenta u PPCI, DES nedvosmisleno imaju prednost nad BMS, naročito kada je u pitanju ponovna revaskularizacija ciljne arterije. To su dokazale i studije COMFORTABLE AMI ${ }^{9}$ EXAMINATION $^{10}$ i NORSTENT ${ }^{11}$ koje su DES stavile daleko ispred BMS (klasa I).

\section{Aspiracija tromba}

Kada je u pitanju aspiracija tromba prilikom izvođenja PPCl, a koja je pripadala Klasi lla, nedavno objavljene studije, TOTAL studija ${ }^{12}$ na više od 10000 pacijenata i TASTE studija ${ }^{13}$ na preko 7000 pacijenata, nisu pokazale benefit od rutinske tromboaspiracije, koja prema aktuelnom vodiču za STEMI ne preporučuje (Klasa III).

\section{Kompletna revaskularizacija}

Višesudovna koronarna bolest je prisutna u $50 \%$ pacijenata sa STEMI. Za razliku od jasne indikacije za primarnu $\mathrm{PCl}$ infarktne arterije, $\mathrm{PCl}$ neinfarktne arterije nije bila jasno definisana. Rezultati četiri randomizovane kliničke studije koje su poredile revaskularizaciju samo IRA i kompletnu revaskularizaciju, PRAMI, CVLPRIT, DANAMI 3-PRIMULTI i Compare acute studija pokazale su redukciju u kompozitnom ishodu i na taj način kompletnu revaskularizaciju iz klase III preveli u klasu lla preporuka.

\section{Farmakoterapija}

Nefrakcionisani heparin je antikoagulantna terapija izbora prilikom izvođenja primarne $\mathrm{PCl}$ (Klasa I). Enoksaparin, zahvaljujući pozitivnim rezultatima ATOLL studije je preveden u višu klasu preporuka, treba ga razmotriti u STEMI pacijenata (Klasa lla), dok su rezultati MATRIX $i$ HEAT-PPCl uticali da se bivalirudin prevede u nižu klasu (iz Klase I preporuka u Klasu lla), dok je i dalje nezamenjiv u PPCl u slučaju heparinom indukovane trombocitopenije (Klasa I).

\section{Rani otpust pacijenata}

Korišćenjem određenih sistema za skoriranje rizika kao što su PAMI II i ZWOLLE, mogu se identifikovati niskorizični pacijenti, za koje se može planirati rani otpust iz bolnice nakon uspešno sprovedene PPCl. Rani otpust se prema preporukama iz 2012. godine odnosio na vreme posle $72 \mathrm{~h}$ (Klasa IIb), a u aktuelnom vodiču ono je kraće i iznosi između 48h i $72 \mathrm{~h}$ (Klasa Ila).

\section{Oksigenoterapija}

Primena kiseonika je indikovana kod pacijenata sa hipoksemijom (Klasa I), ali se rutinska primena kiseonika ne preporučuje (Klasa III) jer hiperoksemija može biti štetna kod nekomplikovanog infarkta uzrokujući miokardno oštećenje [14]. U odnosu na preporuke iz 2012. godine, pomerena je granica saturacije kiseonika ( $\mathrm{SaO} 2)$, kada treba primeniti kiseonik, sa $95 \%$ na $90 \%$.

\section{Nove preporuke}

\section{Revaskularizacija u kardiogenom šoku}

$\mathrm{Na}$ osnovu mišljenja eksperata, kod pacijenata sa kardiogenim šokom treba razmotriti kompletnu revaskularizaciju (Klasa Ila).

2. Odložena implantacija stenta

Rezultati DANAMI 3-DEFER studije ${ }^{15}$, koja je poredila odloženu implantaciju stenta (48h od prve procedure), sa implantacijom stenta u istoj proceduri, pokazali su veću učestalost revaskularizacije ciljne arterije u grupi sa odloženim stentiranjem, iz čega je proizašao zaključak da se rutinsko odloženo stentiranje ne preporučuje (Klasa III).

\section{Farmakoterapija}

Tikagrelor i prasugrel predstavljaju prvi izbor kod pacijenata sa STEMI (Klasa I), dok se klopidogrel preporučuje samo u situaciji kada tikagrelor i prasugrel nisu dostupni ili su kontraindikovani (Klasa I).

Prevođenje sa klopidogrela na potentniji $\mathrm{P}_{2} \mathrm{Y}_{12}$ inhibitor, trebalo bi razmotriti $48 \mathrm{~h}$ nakon fibrinolitičke terapije (Klasa IIb). Može se razmotriti i prolongirana terapija tikagrelorom u periodu do 36 meseci, kod visoko rizičnih pacijenata (Klasa Ilb), na osnovu rezultata PEGASUS TIMI 54 studije $^{16}$.

U situaciji kada nije ordiniran $\mathrm{P}_{2} \mathrm{Y}_{12}$ inhibitor, može se razmotriti primena Kangrelora (Klasa Ilb)

U cilju povećanja adherence, prema aktuelnim preporukama, može se razmotriti primena „polypill” terapije (Klasa Ilb).

\section{Zaključak}

Osnovu novih preporuka čini definisanje „0" vremena, koje predstavlja vreme postavljanja dijagnoze STEMI (zabeležena elevacija ST segmenta ili njeni ekvivalenti), od 
koga započinje odbrojavanje. Sledi reperfuziona strategija koja podrazumeva PPCl unutar 120 minuta ili fibrinolitičku terapiju unutar 10 minuta. Optimalna farmakoterapija, P2Y12 inhibitori, transradijalni pristup, izbegavanje rutinske tromboaspiracije i primena DES predstavljaju osnove $\mathrm{PPCl}$. Kompletna revaskularizacija u slučaju kardiogenog šoka u primarnoj proceduri, a u slučaju višesudovne koronarne bolesti u istoj hospitalizaciji se preporučuje.

Sumirajući zaključke revidiranih starih i novih preporuka, stiče se utisak da su osnovne izmene u preporukama izvršene u cilju skraćenja totalnog ishemijskog vremena, šire upotrebe i postizanja pravovremene i optimalne reperfuzije, smanjena komplikacija i skraćenog hospitalnog boravka.

\section{Literatura}

1. Kristensen SD, Laut KG, Fajadet J, et al. Reperfusion therapy for ST elevation acute myocardial infarction 2010/2011: current status in 37 ESC countries. Eur Heart J 2014;35(29):1957-1970.

2. Armstrong PW, Gershlick AH, Goldstein P, et al. STREAM Investigative Team. Fibrinolysis or primary PCl in ST-segment elevation myocardial infarction. N Engl J Med 2013;368(15):1379-1387.

3. Task Force on the management of ST-segment elevationsacute myocardial infarction of the European Society of Cardiology (ESC), Steg PG, James SK, Atar D, et al. ESC Guidelines for the management of acute myocardial infarction in patients presenting with ST-segment elevation. Eur Heart J 2012;33(20):2569-2619.

4. Bagai A, Jollis JG, Dauerman HL, et al. Emergency department bypass for ST-segment-elevation myocardial infarction patients identified with a prehospital electrocardiogram: a report from the American Heart Association Mission: Lifeline program. Circulation 2013;128(4):352-359.

5. Thygesen K, Alpert JS, Jaffe AS, et al. ESC Committee for Practice Guidelines. Third universal definition of myocardial infarction. Eur Heart J 2012;33(20):2551-2567.

6. Valgimigli M, Gagnor A, Calabro P, et al. MATRIX Investigators. Radial versus femoral access in patients with acute coronary syndromes undergoing invasive management: a randomised multicentre trial. Lancet 2015;385(9986):2465-2476.

7. Jolly SS, Yusuf S, Cairns J, et al. Radial versus femoral access for coronary angiography and intervention in patients with acute coronary syndromes (RIVAL): a randomised, parallel group, multicentre trial. Lancet 2011;377(9775):1409-1420.

8. Romagnoli E, Biondi-Zoccai G, Sciahbasi A, et al. Radial versus femoral randomized investigation in ST-segment elevation acute coronary syndrome: the RIFLE-STEACS (Radial Versus Femoral Randomized Investigation in ST-Elevation Acute Coronary Syndrome) study. J Am Coll Cardiol 2012;60(24):2481-2489.

9. Raber L, Kelbaek H, Ostojic M, et al. Effect of biolimus-eluting stents with biodegradable polymer vs bare-metal stents on cardiovascular events among patients with acute myocardial infarction: the COMFORTABLE AMI randomized trial. JAMA 2012; 308(8):777-787.

10. Sabate M, Cequier A, Iniguez A, et al. Everolimus-eluting stent versus bare-metal stent in ST-segment elevation myocardial infarction (EXAMINATION]: 1 year results of a randomised controlled trial. Lancet 2012;380(9852):1482-1490.

11. Bonaa KH, Mannsverk J, Wiseth R, et al. Drug-eluting or baremetal stents for coronary artery disease. N Engl J Med 2016; 375(13):1242-1252.

12. Jolly SS, Cairns JA, Yusuf S, et al. Randomized trial of primary PCI with or without routine manual thrombectomy. N Engl J Med 2015;372(15):1389-1398.

13. Frobert O, Lagerqvist B, Olivecrona GK, et al. Thrombus aspiration during STsegment elevation myocardial infarction. N Engl J Med 2013;369(17):1587-1597

14. Stub D, Smith K, Bernard S, et al. Air versus oxygen in STsegmentelevation myocardial infarction. Circulation 2015;131(24]: 21432150. Hofmann R, James SK, Svensson L, et al. Determination of the role of oxygen in suspected acute myocardial infarction trial. Am Heart J 2014;167(3):322-328

15. Kelbaek H, Hofsten DE, Kober L, et al. Deferred versus conventional stent implantation in patients with ST-segment elevation myocardial infarction (DANAMI 3-DEFER): an open-label, randomized controlled trial. Lancet 2016;387(10034):2199-2206.

16. Bansilal S, Fish MP, Im K, et al. Long-term use of ticagrelor in patients with prior myocardial infarction. N Engl J Med 2015; 372(19):1791-1800.

Posvećeno počecima primarne perkutane koronarne intervencije na ovim prostorima. Doktori Sreten Grujičić, Zoran Đurišić, Petar Pejčić, Dragan Benc, Miodrag Obradović i Robert Jung su uradili perkutanu koronarnu intervenciju kod bolesnika sa akutnim infarktom srca i ST elevacijom donjeg zida 23. maja 1982. godine u Institutu za kardiovaskularne bolesti Sremska Kamenica. 